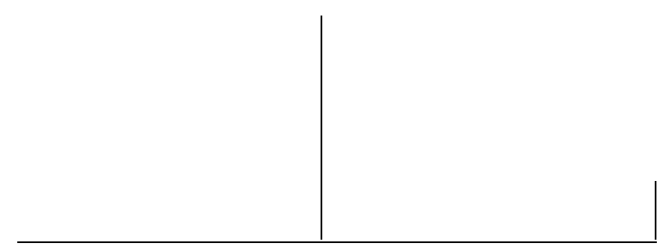

Rev. Latinoam. Psicopat. Fund., IX, 2, 203-226

\title{
Próteses psíquicas: a psicofarmacologia como biotecnologia e a téchne trágica da psicanálise
}

\author{
Glaucia Dunley
}

\begin{abstract}
Considerando a relevância do estudo das próteses na cultura informacional contemporânea, e aproximando-o do campo psicopatológico através da idéia dos psicofármacos funcionando como próteses psíquicas, pretendo problematizar a inserção das novas tecnologias - especialmente as biotecnologias, como a psicofarmacologia - no projeto de longa duração da metafísica, descortinando a lógica da vontade de poder em jogo, e suas máscaras. Procurando formas de resistir a esta disponibilização sem fim do real, pela qual o próprio sujeito se vê atingido, objetivando-se das mais variadas formas, a psicanálise se configura como téchne trágica, herdeira de uma transmissão estética e ética da existência, propondose a restituir ao homem contemporâneo um saber sobre a sua própria tragicidade, pela qual seria possível afirmar um bem-viver em que a dor de existir não ficaria encoberta.
\end{abstract}

Palavras-chave: Psicofarmacologia, vontade de poder, disponibilização, pânico 


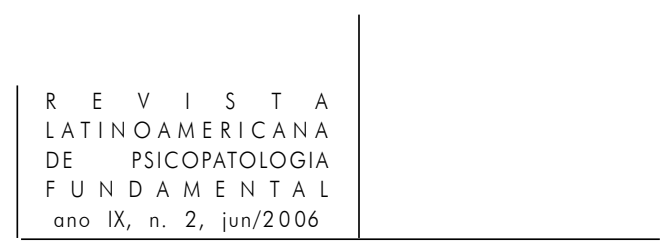

\section{Apresentação}

Este trabalho é uma derivação de minha tese de doutoramento, ${ }^{1}$ onde procurei aprofundar minha inquietação a respeito dos sentidos e dos destinos de uma contemporaneidade marcada pelas novas tecnologias, signo paradoxal de seu mal-estar e de sua potência. Naquele contexto, tomei as próteses em sua generalidade como figuras argumentativas de uma contemporaneidade mergulhada no que chamei de festa tecnológica, na esteira da afirmação trágica de Nietzsche "Deus está morto", com isto significando o tempo de desamparo sem véus que sobreveio à quebra das garantias simbolicamente fornecidas pelos discursos de legitimação (religiosos, filosóficos, grandes narrativas), nos séculos XIX e XX, assim como às várias formas de dissolução do eu. Para além do desamparo, configura-se o abandono do contemporâneo a uma lógica da eficácia, provocada pela tecnologia.

Em seu belíssimo texto "A grande recusa”, Blanchot nos fala do contemporâneo como de um tempo em que "os deuses faltam, e no qual nós nos desviamos cada vez mais da presença passageira para nos afirmarmos num universo construído à medida do nosso saber... capaz de nos conceder um futuro sem morte ou uma lógica sem acaso... este acaso que nos dá sempre medo, porque esconde $a$ obscura decisão". Este pequeno fragmento tem valor de denúncia, dirigida a uma contemporaneidade que se crê a salvo do acaso, do

1. "O pensamento trágico e a crítica da cultura - o paradoxo das próteses na cultura informacional contemporânea”. Tese de Doutoramento em Comunicação e Cultura defendida em agosto de 2003, na Escola de Comunicação/UFRJ. Como livro já publicado tem o título A festa tecnológica. O trágico e a crítica da cultura informacional (São Paulo: Escuta/Rio de Janeiro: Fiocruz, 2005). 
horror do acaso, ou do pânico como experiência do terror diante de uma existência sem garantias, como efetivamente ela o foi desde sempre - verdade esta dissimulada pela "lógica sem acaso" da tecnologia, sobre a qual estaria falando Blanchot.

Em outras épocas, na aurora do pensamento ocidental, diferentemente de nós contemporâneos que respondemos maciçamente a este desamparo colocando o excesso pulsional a serviço da indiferenciação, da reprodução, da medicalização da cultura, os gregos a ele responderam esteticamente com a criação da grande arte trágica - palco do inesperado, das metábole $e^{2}$ ou peripécias acontecidas nas oposições da "fala contra fala". ${ }^{3}$ Deste modo, a tragédia mostrou explicitamente a linguagem como fonte permanente de duplos sentidos, de equívocos, a partir dos quais a existência do personagem mudava radicalmente, levando-o do desamparo à perdição, e trazendo com isso o ensinamento de que o acaso é soberano em relação a qualquer suposta garantia, inclusive e especialmente às que seriam dadas pela linguagem.

É verdade que os gregos - com Sócrates e Platão - responderam também politicamente ao caos da existência - paixão da tragédia - com a criação da metafísica - o maior aparelho de dizimar diferenças e o sensível em geral, incluindo nele o corpo e seu pathos - numa tentativa, que já dura 24 séculos (se nela inserirmos o hiperdesenvolvimento contemporâneo da técnica, como o quer Heidegger), de destituir a existência de seus terrores, do sensível que nos conduz inexoravelmente à morte como obscura decisão do acaso, da qual fala Blanchot. Colocando-nos assim - por este saber petrificado e pretensamente garantido sobre o real, e do qual a tecnologia contemporânea é a figura máxima e escatológica - ilusoriamente ao abrigo da morte e do medo da morte.

Desde já, acredito ter ficado explícita a relação que pretendo fazer entre a lógica da eficácia - que a paixão da contemporaneidade pela tecnologia reflete -

2. O termo peripécia, do grego peripethéia, e que tem sentido equivalente ao de metábole (inversão da situação), designa um dos principais artifícios utilizados pelos poetas trágicos na estruturação do mythos (enredo) da tragédia para alcançar o efeito de perdição do herói trágico. A partir de uma determinada fala, o herói tornava-se vítima da hamartia (literalmente, erro de alvo), e tudo mudava radicalmente para ele, invertendo a situação, e levando inarredavelmente à perdição. $\mathrm{O}$ mythos trágico possuía assim uma função de mostrar e ensinar aos gregos, pela arte, a total falta de garantias da existência, inserindo o homem desde sempre na dimensão trágica do desamparo.

3. Em Observações sobre Édipo, Hölderlin destaca o caráter de oposição da fala humana na tragédia Édipo-Rei, de Sófocles, que ele traduz pouco antes de enlouquecer, no início do século XIX, dizendo que esta "fala contra fala” é signo da separação entre o humano e o divino, inauguradora de um tempo trágico, cujo início ele detecta no teatro de Sófocles, mas que também é moderno. 


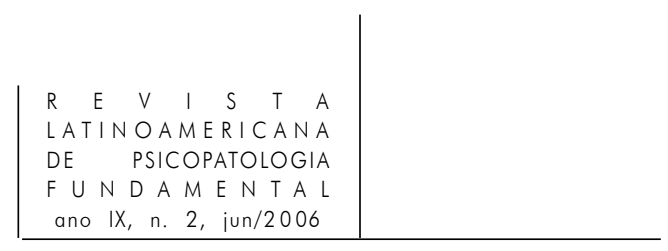

e esta lógica sem acaso, produto da vontade de poder que obrou e ainda obra a metafísica moderna como sua essência.

É neste contexto que passo a considerar o hiperdesenvolvimento da psicofarmacologia como o de uma biotecnologia que compartilha deste desejo de eficácia da contemporaneidade - nostalgia talvez do desejo de garantia. Ao contribuir de forma crescente para rejeitar as representações e reprimir os afetos relativos às condições reais da existência, o hiperdesenvolvimento da psicofarmacologia e a disseminada utilização dos psicofármacos - assim como qualquer outra tecnologia investida pela mesma vontade - estariam implicados no retorno dessas representações e afetos no real (do corpo dos sujeitos e do "corpo da cultura”), seja sob a forma sintomática de irrupções de angústia do dito Transtorno do Pânico ao nível do sujeito, seja sob outras formas relacionadas ao terror, ao nível da cultura, inclusive o terrorismo.

No decorrer do texto abordo o caráter de mímese ou caráter mimético desta forma de biotecnologia que permite - como a toda téchne é permitido - um duplo funcionamento e, portanto, uma diferente utilização: como suplemento, no caso, na neurotransmissão, ou como suplente/substituto dos neurotransmissores - esta última forma ou função constituindo o que denominei de prótese psíquica no atual estado de medicalização da cultura, se assim posso dizer. ${ }^{4}$

Antecipo neste momento o que me parece estar em jogo no Transtorno do Pânico, como categoria psiquiátrica cujo surgimento se deu aproximadamente há duas décadas, e que não cessa de interpelar a psicanálise e a filosofia na direção de sua desnaturalização. Em consonância com as elaborações que aqui desenvolvo em torno da cultura contemporânea, e também freudianamente, estas irrupções de angústia seriam produzidas maciça e automaticamente por um eu que se vê abruptamente lançado nas suas verdadeiras condições de existência, ou tomado de assalto por um saber inconsciente sobre as mesmas. Nestas crises ou ataques, o sujeito experimenta uma ansiedade extrema, sem razão explicável, sensação de morte iminente, medo de enlouquecer, acompanhados por sintomas físicos intensos como taquicardia, falta de ar, asfixia, opressão torácica, tremores, vertigem.

Talvez com esta hipótese, acrescida do que mais adiante trabalho como desmoronamento do simbólico, seja possível compreender a predominância na atualidade destas formas desencadeadas de angústia - nomeadas por Freud de Real-Angst e que traduzo, à luz do que proponho, por angústia do real, onde o

4. Esta eleboração baseou-se na leitura de A imitação dos modernos, de P. Lacoue-Labarthe. Por sua vez, muitas das elaborações apresentadas neste denso e instigante livro derivam do aprofundamento feito pelo autor da Física B, de Aristóteles. 


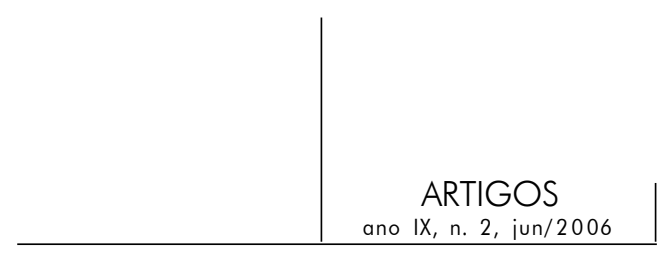

real é um objeto terrífico incognoscível, inapreensível e fonte de toda indeterminação (Rosset) sobre as formas crônicas e flutuantes que ele descreveu no contexto das neuroses atuais no final do século XIX (Costa Pereira, "O pânico e os fins da psicanálise”).

É, a meu ver, este saber sobre o real que a medicalização da cultura visa eliminar, funcionando como uma metafísica de laboratório, e impedindo-nos de buscar, na fonte pática da existência, as saídas criativas para o inarredável desamparo.

\section{Objetivos}

Tenho como objetivos neste texto discutir algumas idéias:

1) A psicofarmacologia em seu hiperdesenvolvimento é uma biotecnologia a serviço do poder difuso da "sociedade de controle" de Foucault e Deleuze, ou da sociedade globalizada. Esta última será aqui abordada como um dos destinos da vontade de poder, considerada por Heidegger a penúltima etapa da vontade de vontade, vontade que se quer a si própria, procurando no mesmo as garantias de sua autoperpetuação, e que constitui o motor ou a essência da metafísica moderna e da técnica. Deixo desde já assinaladas a aproximação possível desta vontade com a pulsão de poder e a pulsão de morte freudianas.

Segundo ele, esta vontade é a responsável por idealizar e formalizar (endurecendo) o projeto tecnocientífico moderno de disponibilização do real (incluindo nele o próprio homem), através de instituições de toda ordem, nos séculos XIX e XX, que organizaram freneticamente os saberes e as produções em geral, centralizando-os (nas instituições). Considero possível articular este pensamento vigoroso de Heidegger ao de Foucault, abrindo para que novas possibilidades ou configurações desta mesma vontade de poder passem a operar agora na "sociedade de controle" nos moldes de um poder difuso, capilar, mas extremamente infiltrante ao nível do biológico, do somático, do psicobiológico.

2) O projeto de naturalização do psiquismo, assentado nas bases acima referidas, pode ser pensado como destino (da essência) da técnica e do saber científico, em seu hibridismo de tecno-logia - unindo a técnica moderna e a lógica científica - sendo portanto uma produção da vontade de poder em vigor como tal desde o primeiro moderno. Solidariamente a este pressuposto heideggeriano, Foucault, em A história da sexualidade, ao desconstruir a hipótese repressiva do poder, diz que o poder é produtivo. O poder produz discursos, diz ele. E afetos, eu acrescentaria. Em nosso contexto contemporâneo, discursos biologizantes: o da psicofarmacologia (que leva a prática psiquiátrica ao estado 


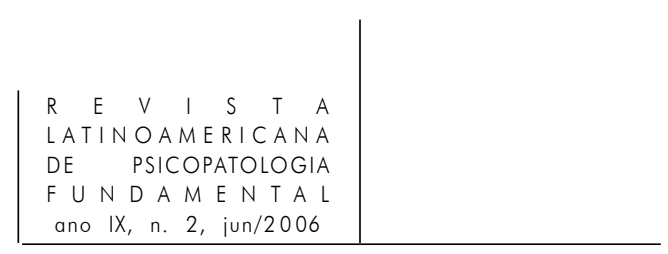

de psiquiatria biológica, por exemplo), o da neurolingüística, o do cognitivismo, o da psicologia experimental, e os das neurociências em geral.

Todos eles, evidentemente, contribuem para a abolição da dimensão trágica da existência e com ela o amor pela diferença, pelo acaso, pelo outro, e pela paixão que vem dele.

3) A psicanálise, inicialmente um projeto científico do próprio Freud, é, por sua inserção junto às ciências do século XIX, rebento da metafísica, e com ela compartilha, de forma ambivalente, o desejo de poder através do qual procura se assegurar das certezas e garantias. Entretanto, como herdeira explícita da grande arte trágica de Sófocles, a téchne psicanalítica ultrapassa seu destino metafísico (de provocar a ciência psicanalítica a ir na direção da desmesura do saber, petrificando suas formas e conceitos em um saber muito organizado), e se afirma como uma téchne trágica. Isto é, como uma estética, uma ética e uma política da finitude, questionadoras incansáveis do ceticismo e do niilismo moderno/contemporâneo.

Como tal, a psicanálise faz resistência à disponibilização crescente dos sujeitos na cultura, isto é, em seu mal-estar, interpelando-os ou convocando-os a resgatarem sua tragicidade, o que implica poder afirmar a sua divisão, seus impasses, suas impossibilidades. Sem álibis e dissimulações.

4) Através desta possibilidade, dada por uma psicanálise fundada no saber trágico de Sófocles e de Freud - que se situa muito além da problemática do incesto e da interdição, pois se abre para repensar a relação desmesurada do homem com o saber, que em absoluto não o garante do acaso e do desamparo, caso de Édipo propriamente - tentar desnaturalizar o Transtorno do Pânico. Este é aqui compreendido como signo de uma contemporaneidade mergulhada na desmesura tecnológica e na paixão pela eficácia, tentando fazer com isso suplência das garantias outrora concedidas pelos discursos que reconheciam na transcendência um valor positivo. Esta dimensão contemporânea de dissimulação do real, ou da verdade, rejeita o Phobos como força primordial, fazendo-o retornar então sob as formas sintomáticas ou degradadas do Transtorno do Pânico ao nível do sujeito, e do Terror ao nível da sociedade mundial globalizada.

\section{Desenvolvimento}

A vontade de poder da metafísica e a derrocada dos valores supremos - "A morte de Deus”

Acredito que resida na trama que inclui o imbricamento entre metafísica, técnica, niilismo, vontade de poder, terror, vontade de potência, eterno retorno 
como face positiva ou afirmativa da repetição, e a declaração da morte de Deus a possibilidade de inserir a metapsicologia das pulsões, esta mitologia da razão freudiana, no projeto historial de longa duração do Ocidente (24 séculos de metafísica), permitindo-lhe encontrar efetivamente seu valor, seu sentido e sua diferença na medida em que a sua historicidade é reconhecida como pertencente a este processo, nem que seja para lhe fazer resistência, como forma de pensamento trágico na passagem da Modernidade para a Contemporaneidade (Dunley, 2001). Sem o que, a psicanálise não estaria habilitada constitutivamente para participar deste tipo de análise da cena contemporânea.

Lembro apenas que o modo de funcionamento da psicanálise reflete esta dupla inscrição: ela é tanto herdeira do legado trágico grego, quanto rebento do projeto metafísico - no qual se inscreveu como ciência moderna -, e com o qual ela se relaciona de forma ambivalente, ora participando de suas certezas e de sua vontade de objetivação, ora resistindo-lhe como pensamento da diferença e paixão do paradoxo, como o atestam os seus diversos momentos.

Talvez só assim - neste encadeamento onde tal paradoxo torna-se manifesto - possa-se pensar com alguma gravidade sobre as chamadas novas formas de subjetivação, que mal escapam de serem taxadas de novas subjetividades como correlato ou contrapeso explícito das novas tecnologias.

Só assim também, e com a mesma gravidade, possamos nos deter nas novas formas de sociabilidade em um mundo dito sem Deus por Nietzsche, ao constatar o niilismo dominante na Modernidade já se vão pouco mais de cem anos, proveniente da derrocada dos valores supremos (indicada e perpetrada em grande parte por ele próprio, com o seu martelo).

Em "O insensato", aforismo 125 de A gaia ciência (publicada em 1882, um ano antes de Zaratustra), Nietzsche se refere pela primeira vez "à morte de Deus”, como a constatação do niilismo na Modernidade, proveniente da já comentada desvalorização dos fundamentos que outrora sustentavam o projeto ocidental. A fé no Deus cristão e toda crença no supra-sensível deixaram de ser plausíveis, na medida em que foi constatada a impossibilidade de realização desse mundo ideal. A efetividade desses valores tornou-se incerta, até que acabaram por se mostrar como valores sem eficácia, já que não garantem as vias e os meios de realizar os fins por eles propostos. Isto entra em rota de colisão com a essência da metafísica, que é, como vimos e segundo Heidegger, uma vontade de poder que procura se afirmar pelas certezas e garantias, e onde, para ele, residiria a essência do niilismo. Isto certamente daria sentido a uma substituição dos valores do mundo supra-sensível pela "civilização" tecnológica da contemporaneidade, no ápice da sua vontade de controlar a vida pela técnica, e onde se procura encontrar um grau de eficácia jamais concedido pelos discursos fundados nos valores supremos. 


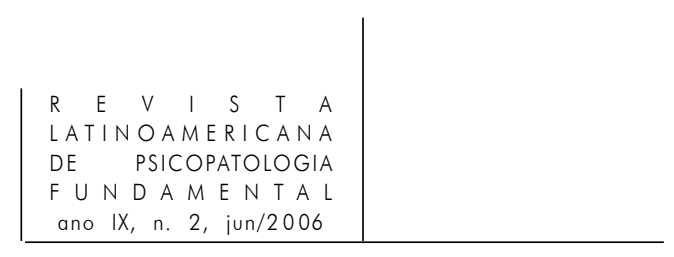

Acredito que vivemos atualmente em meio a um deslocamento das forças comprometidas no jogo ambivalente do homem em relação às idéias de garantia (que estão por trás destes valores supremos), e das quais a idéia de Deus é o carro-chefe em relação aos outros "mais altos valores" (como o Bem, a Verdade, a Eternidade, o Ser), também em declínio ou em descrédito.

Este deslocamento que se manifesta como endurecimento em favor das certezas ou garantias (embora toda uma aparente flexibilização), e não da potência de criação - que pressupõe o reconhecimento do desamparo como fonte pática de realizações -, esteja talvez na origem da falta de estranheza com que as sociedades contemporâneas experimentam os extraordinários feitos da tecnologia (já prenunciados por Freud em “O mal-estar da civilização”), banalizando-os, ou naturalizando-os.

\section{O início da naturalização do psiquismo e o da desvalorização do simbólico}

Baseada em alguns pressupostos já apresentados, e em outros que passo a apresentar, procuro mostrar a longa duração do projeto de naturalização do psíquico. Ou seja, ele é muito anterior ao advento da psicofarmacologia moderna, ocorrido em meados do século XX, com a descoberta dos efeitos antipsicóticos da clorpromazina, e de sua revolução, desencadeada pelo acontecimento das neurociências na década de 1970. Estas últimas foram retroalimentadas pela explosão de biotecnologias que passaram a investigar o Sistema Nervoso sob seus vários aspectos - entre elas, a psicofarmacologia.

Tomando um impulso desmesurado com o modelo da neurotransmissão no final da década de 1960, esta técnica de investigação do SN se debruça sobre a descoberta de substâncias que possam mimetizar o funcionamento dos neurotransmissores, mapeando seus locais de ação e assim informando as neurociências sobre o funcionamento do $\mathrm{SN}$, e a medicina sobre as doenças em questão. Precisamente, permitiu à psiquiatria aceder ao estatuto científico de outras disciplinas médicas, através de sua vertente biológica, a Psiquiatria Biológica - até pouco tempo antes apenas um campo da psiquiatria dedicado ao estudo dos fundamentos neurobiológicos da atividade psíquica -, tornando-a uma concepção abrangente dentro da Psiquiatria Clínica (Bogochvol). Com isto, os distúrbios ou transtornos mentais seriam resultantes de alterações da neurotransmissão em determinados micro-ambientes do cérebro. Através da psicofarmacologia, estes transtornos poderiam ser corrigidos, levando os usuários não só a uma resposta positiva, mas a uma remissão dos sintomas, sempre buscada, indo na direção de se atingir o bem-estar, como meta possível dentro da lógica da eficácia presumida como um valor pela psicofarmacologia. Para os 
defensores do biologismo, aqui considerado uma ideologia cientificista, e constituindo uma das concepções mais influentes da Psiquiatria Biológica, o sintoma psíquico e o próprio psiquismo seriam de ordem biológica, não existindo uma ordem propriamente psicopatológica, dando lugar a uma "psiquiatria sem psiquismo” (Bogochvol).

Faz-se necessário, neste momento, um recuo onde a psicofarmacologia será a figura argumentativa das relações entre técnica e ciência modernas, cujo imbricamento traduz a engrenagem da vontade de poder. Tudo isto vai ao encontro, portanto, do caráter ideológico desta composição, e das implicações éticas do hiperdesenvolvimento da psicofarmacologia.

Neste longo recuo, Heidegger é um interlocutor poderoso. Através de algumas de suas colocações será possível compreender e fundamentar uma de minhas afirmações anteriores de que a eficácia da era tecnológica é nostalgia da garantia buscada através da edificação dos valores supremos - todos simbólicos - que vigoraram durante 24 séculos, ou, em outras palavras, ela é sua suplente. Eficácia tecnológica podendo ser definida neste contexto como aquela que produz efeitos rápidos e seguros - de ordem real e imaginária -, sem que se considere a qualidade e as implicações dos mesmos, a ponto de desvalorizar e praticamente eclipsar a eficácia simbólica, como valor permanentemente estruturante dos sujeitos e da cultura.

Minha hipótese é que a eficácia simbólica ou a eficácia do simbólico em operar o reconhecimento das diferenças e dos lugares, agora em descrédito, desmoronou junto com os valores transcendentes não mais considerados eficazes para realizar sua função: garantir a existência contra os seus inevitáveis abalos. Estes valores permaneceram incólumes até a modernidade, quando o sonho de poder e autonomia do homem, alimentado pelo saber científico, colocou-o pretensamente como senhor da natureza, fazendo-o abrir mão gradualmente de uma exterioridade transcendente que o garantisse e da qual ele dependesse. A paixão pela ciência colocou a antiga transcendência na imanência das ciências e das técnicas. Deste modo, a sentença nietzschiana "Deus morreu" deve incluir também a "quebra" do simbólico como valor transcendente. Veremos mais adiante como esta transcendência, não mais divinizada, ainda assim se constrói no contemporâneo.

Acredito que este acontecimento que envolveu o simbólico tenha como acontecimento correlato a proeminência dos outros dois registros - o real e o imaginário - nas manifestações humanas ao nível do sujeito e da cultura, inclusive as do corpo e do psiquismo. Esta nova configuração permitiria compreender melhor a emergência de certos fenômenos (além dos dois já assinalados), como, por exemplo, o aumento da incidência de doenças ditas psicossomáticas e das adições/compulsões. 


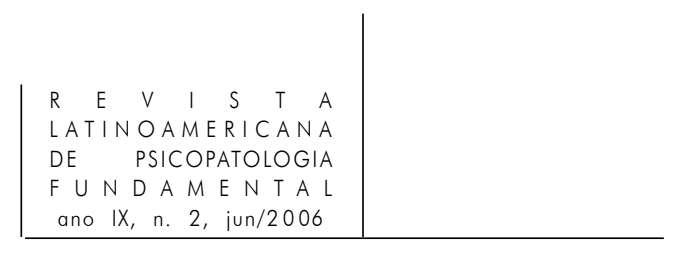

Por um pequeno deslocamento, talvez se possa pensar que a eficácia (imaginária) tecnológica passe a fazer função de suplência do simbólico sobre o qual se baseava a autoridade transcendente do primeiro dos fundamentos, do Fundamento Supremo - do Verbo - que era, supostamente, a fonte de toda garantia. Temos então um real cujo véu está esgarçado por sua (in)consistência predominantemente imaginária, deixando-nos talvez pensar que não estamos mais protegidos pelo simbólico. Na verdade, nunca estivemos. Este é o grande ensinamento concedido pela arte trágica grega.

Estas considerações me levam a retomar a questão da função simbólica hoje, diante da indiferenciação reinante na era do hiperdesenvolvimento tecnológico. Segundo Lebrun (2002), o simbólico constitui as diferenças e as diferenças de lugares. É na linguagem, na fala, que alguém marca sua diferença, advindo-lhe por conseguinte a autoridade de falar deste lugar diferente, que poderá ou não ser reconhecido como legítimo.

Ora, no cenário de uma sociedade mundial globalizada, esta função foi radicalmente desvalorizada, juntamente com os outros valores transcendentes. É preciso questionar a possibilidade de se falar de mudança de regime do simbólico - que Lebrun chama de mutação do simbólico - e as suas implicações nas novas configurações entre corpo e cultura. Ela abrangeria inclusive e muito especialmente a questão: o que se diz quando se fala de "novas patologias" ou de "novas formas de subjetivação"?; assim como a desvalorização ou deslegitimações dos valores tradicionalmente reconhecidos como eminentemente simbólicos, entre eles a autoridade das gerações precedentes, a dos professores, dos mestres, dos livros! Ou, muito simplesmente, da palavra. Minha interpretação pretende mostrar neste pequeno desenvolvimento que esta transformação foi gradual e planificada.

Segundo ainda esse autor (Lebrun, 2003), teríamos passado de um regime social eminentemente simbólico - em que o lugar da exterioridade e da transcendência estava garantido supostamente - para um sistema no qual este lugar está esvaziado, desvalorizado, perdido na imanência do confronto entre opiniões. Mais do que isto, porque não dizer, este lugar vazio é odiado, e passa a ser preenchido pelos pequenos e grandes confortos e satisfações mediados pela tecno-lógica da eficácia.

Em seu instigante artigo "La haine de la haine”, Lebrun se questiona sobre o quê ou sobre quem incidiria o ódio originário, anterior ao amor. Diz então que o ódio é em primeiro lugar ódio do simbólico, da linguagem, pois implica furo, vazio.

Mais precisamente, passagem de um regime simbólico vertical - hierárquico pela marcação de lugares diferentes, onde o lugar da transcendência era evidente e espontaneamente reconhecido como legítimo - para um simbólico horizontal, 


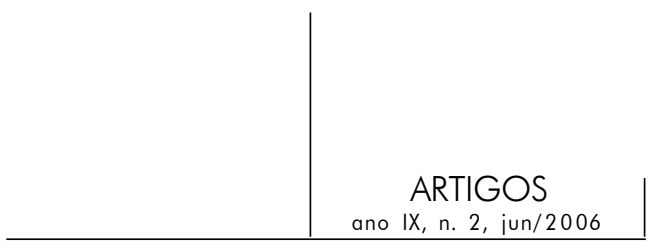

imanente, não necessariamente sem alguma transcendência ou sem referência a ela. Qual seria agora a natureza desta transcendência, se ela não é mais da ordem do divino ou da divinização dos valores?

Esta nova transcendência - este Fora - é construída de dentro, mas como forma de nomear algo que é exterior ao sistema, aquilo que lhe é heterogêneo, e que está sempre em posição de dissimetria. O lugar do Fora é o Fora do lugar dos outros, talvez o lugar do vazio.

Freud desloca esta exterioridade para o íntimo do sujeito, trazendo as pulsões - nossos daimons - para este lugar de ex-timidade, do Fora dentro, tornando-nos descentrados constitutivamente. Assim a psicanálise é a paixão do simbólico, paixão do vazio, em torno do qual se fala - é saber trágico que reconhece uma transcendência tornada íntima, mas nem por isso sob controle. Ao contrário, ela nos desaloja continuamente, privando ou desapossando o eu de seu desejo de estabilidade, de garantia contra o perigo mais temível e angustiante, que vem desta exterioridade íntima, e da qual não de pode fugir - o perigo pulsional -, nivelando nosso desamparo ao do herói trágico diante da onipotência do destino e da vontade de poder dos deuses.

Para o grego trágico, o homem é constituído de ethos e daimon. Onde ethos é o conjunto de práticas, pensamentos e ações que colocam o homem na direção do eu prattein (do bem-agir e do bem-viver), enquanto os daimons são as forças implacáveis do destino e do divino, que o tornam completamente vulnerável ao erro (hamartia), e à perdição apesar de todo o ethos - lugar do simbólico.

A desautorização do simbólico iniciou-se, na verdade, no século XVI, com o processo Galileu. Naquele momento, a palavra de Deus, enunciada pelo Papa, viu-se confrontada com a incipiente, mas revolucionária lógica científica, isto é, com a coerência de fatos e argumentos entrelaçados numa lógica da razão, destituindo de sua hegemonia a palavra proferida em nome de valores transcendentes.

A autoridade da ciência, sempre impulsionada pela técnica, dá ao homem um sentimento de maior legitimidade quando se trata do valor garantia, estando a ciência menos exposta ao risco, uma vez que ela pode apelar para o registro de provas, do qual é hoje um exemplo paradigmático o teste de DNA. Pela biotecnologia, um pai passa a ser pai ou não, independentemente dele se dizer pai ou não, desvelando e marcando este horror ao simbólico na sua função mais primordial: a de reconhecer ou não um filho.

Vejamos agora de uma forma mais minuciosa esta naturalização do psiquismo, inscrita há muito, por minha leitura de Heidegger, no projeto metafísico. Para isto, é preciso examinar a cesura - interrupção ou suspensão que a ciência moderna efetuou na relação do homem com a physis, este Outro com o qual o homem originariamente teve uma relação imanente, passando a

213




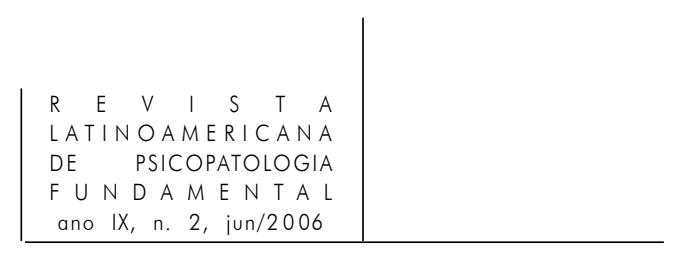

transcendente, e voltando, no primeiro moderno, à imanência causada pelo advento da ciência moderna, alimentada pela técnica. Entretanto, tratava-se de um outro modo de imanência, diferente da imanência do mundo grego da presença, habitado por deuses, homens e outros seres. A partir do século XVII, a relação de imanência do homem com a physis será marcada crescentemente pelo tormento e pela disponibilização da Natureza, posta já a serviço do sonho de poder e de domínio do homem.

Diferentemente da ciência antiga que era teorética, apenas contemplando os seres naturais, sem pensar em intervir sobre eles, e onde a técnica era limitada a práticas necessárias à vida, nada tendo a oferecer à ciência nem a receber dela, a ciência moderna nasce vinculada à idéia de intervir na natureza, de conhecê-la para apropriar-se dela, para controlá-la e dominá-la. Haja vista as afirmações de Francis Bacon para quem saber é poder e a de Descartes para quem a ciência transforma o homem em senhor da natureza. A nova ciência dos séculos XVIXVII era assim inseparável da técnica transformada em tecnologia pela utilização do saber científico. Deste modo, com o advento da tecnologia já no primeiro moderno, surge o embrião da fusão (da hibridização) entre saber-fazer (da técnica) e o saber-saber (do conhecimento científico).

O espaço da ciência moderna é definido pela geometria, sendo, portanto, 214 homogêneo, não havendo "lugares", qualitativamente diferenciados; os objetos físicos são paulatinamente purificados de todas as suas qualidades sensíveis, pois estas são meramente subjetivas.

Enquanto a ciência antiga possuía um ideal de cientificidade baseado na idéia de que a ciência é uma representação do real tal como ele é em si mesmo, a ciência moderna baseia-se na idéia de que o objeto científico é um modelo construído e não uma representação do real. Na filosofia, o regime de representações em vigor é o signo, apontando para a ausência do real.

O ideal científico permitiu à ciência ocupar o lugar de confiança (ou de crença) que a cultura ocidental depositou na razão como capacidade para conhecer o real, mesmo que este tenha que ser inteiramente construído pela atividade racional.

Diferentemente do ideal científico, a ideologia cientificista é decorrente do senso comum, onde se ignoravam e ignoram as complexas relações entre ciência e técnica, sendo costume identificar as ciências com os resultados de suas aplicações. Ou seja, a ideologia cientificista promove a idéia de eficácia, a confusão entre ciência e técnica, e a ilusão de neutralidade científica. O cientificismo é então da ordem da crença. Crença de que a ciência pode e deve conhecer tudo, sendo colocada no lugar de fundamento do conhecimento, no lugar de Deus - a assim chamada razão iluminista pela Escola de Frankfurt. Talvez seja este lugar, e a substituição que nele ocorre, o que autoriza o homem moderno 
e contemporâneo a manipular tecnicamente o real, sem limites para a sua ação a tomar o real como disponibilidade, segundo Heidegger, a propósito da técnica moderna -, e com isso transformando a razão iluminista em razão instrumental, onde o projeto tecnocientífico torna-se um instrumento de dominação, poder e exploração consumada da natureza e do homem.

Esta ideologia (cientificismo) acabará por criar na contemporaneidade uma mitologia da ciência, onde esta não é mais considerada pelo esforço e pelo trabalho em direção ao saber (ideal científico), mas por sua eficácia nos resultados apresentados como espetaculares e miraculosos. Sobretudo por constituir uma forma de poder social e de controle do pensamento (sociedade de controle). Haja vista a importância estratégica neste sentido da "neutralidade científica" que procura dissimular a origem e a finalidade da maioria das pesquisas destinadas a controlar a natureza e a sociedade, seguindo os interesses dos grupos econômicos. O "atormentar a natureza”, assinalado por Bacon no século XVII, toma proporções inusitadas com a ciência contemporânea, já que esta não se contenta em conhecer as coisas e os seres humanos, mas procura construí-los artificialmente, criando inclusive doenças como o Transtorno do Pânico com o objetivo de render lucros ao capital.

O imbricamento essencial entre a metafísica e a técnica nos é oferecido por Heidegger em vários momentos de sua obra. ${ }^{5}$ Destaco apenas que em "A época das concepções de mundo” (1938) Heidegger afirma que o saber moderno é, em primeiro lugar, um saber incondicionado, não se ligando a nenhuma condição exterior a ele próprio para firmar a sua posição de certeza como, nos gregos, ele se ligava à presença ou à ausência imediata do ente, ou à vontade divina na Idade Média. Ele é, antes de tudo, ciência que, em um sentido muito preciso, requer uma certeza absoluta, capaz de fixar o modo de seu progresso (como ciência positiva). E sobre o quê repousaria a essência da ciência moderna, diferentemente da ciência grega e da doutrina da Idade Média? Diz Heidegger que a essência da ciência moderna é a investigação. Por isto não se deve compreender apenas o método, mas o projeto e o rigor dos quais ele depende. A ciência moderna torna-se então investigação (ou experiência exploradora moderna) pelo projeto que se certifica de si próprio a partir do rigor da investigação. Entretanto, projeto e rigor só se desenvolvem a partir do método, criando uma interdependência.

Um outro processo fundamental que determina a ciência moderna é o movimento de exploração organizada (das Betrieb), que se faz dentro de institutos.

5. Os desenvolvimento destes aspectos encontram-se em Dunley, Glaucia. A festa tecnológicaO pensamento trágico e a crítica da cultura informacional. 


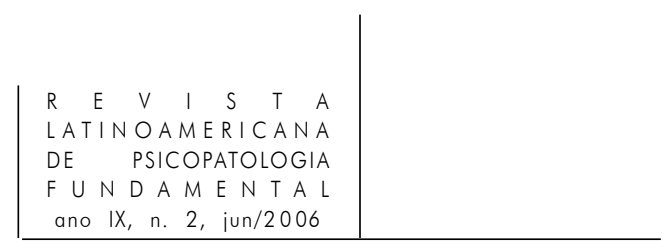

O caráter "institucional" das ciências provém deste movimento crescente de exploração organizada, que assegura a primazia do procedimento (protocolo, metodologia, planificação) sobre o ente, que se torna então objetivo pela investigação. Com isto, a figura do sábio desaparece, sendo substituída pela do pesquisador, comprometido com os programas de pesquisa, e tornando-se um técnico. Apenas desta forma ele permanece eficaz, efetivo e real no espírito da época. A universidade sofre os efeitos deste programa de objetivação, tornandose real e eficaz apenas se tornar possível e visível a separação entre todas as ciências, que se particularizam. As verdadeiras forças da ciência moderna tornamse claramente efetivas na organização da exploração científica.

Ele examina o surgimento de uma teoria do conhecimento no seio da metafísica, e o atribui à objetivação do ente que se torna então cognoscível (pela possibilidade de presença do objeto no e para o conhecimento, garantida pela representação), permitindo reconhecer neste texto de 1938 as colocações que se tornarão explícitas em "A questão da técnica” (1953) quando este "demandar ao ente que dê contas de sua disponibilidade para a representação" se formula como pôr o ente sob o regime da razão - Ge-stell, e será reconhecido como essência da técnica moderna, essência igualmente da metafísica moderna.

\section{A "sociedade de controle" na consumação da metafísica}

Estas elaborações em torno da técnica e da tecnologia como consumação da metafísica, possibilitadas pelo pensamento de Heidegger, encontram, sob certos aspectos, uma continuidade na análise que Foucault realiza sobre o paradigma de poder que vigora na contemporâneo: o biopoder - esta forma de poder que sucedeu a sociedade disciplinar, ${ }^{6}$ e que regula a vida social de dentro e por dentro, acompanhando-a passo a passo, absorvendo-a internamente, transformando a própria vida em objeto de poder com a finalidade de reproduzi-la.

"Devemos entender a sociedade de controle como aquela que, ao se desenvolver nos limites da modernidade e abrindo-se para o contemporâneo, pratica mecanismos de comando cada vez mais 'democráticos', cada vez mais

6. A sociedade disciplinar é aquela na qual o comando social é construído mediante uma rede difusa de dispositivos ou aparelhos que produzem e regulam os costumes, os hábitos e as práticas produtivas: as instituições disciplinares - como a prisão, a fábrica, o asilo, o hospital, a escola, a universidade. Este poder sanciona ou prescreve comportamentos normais e/ou desviados. Foucault não realiza explicitamente em sua obra a passagem da sociedade disciplinar para a sociedade de controle. É Deleuze em Foucault (1986) e em "Post-scriptum sur des sociétés de contrôle”, em Pourparleur (1990). 


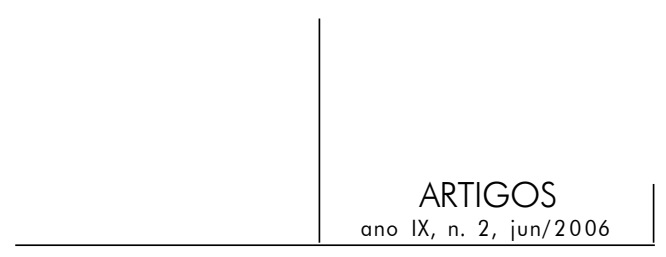

imanentes ao campo social, distribuídos pelos corpos e pelos cérebros dos cidadãos”, diz-nos Negri e Hardt.

É nesta sociedade descrita por Foucault e Deleuze, e retomada por Negri e Hardt (2003, p. 42-3) que as biotecnologias contemporâneas encontram seu desenvolvimento e seu sentido. O poder agora é exercido mediante máquinas e técnicas que organizam diretamente o cérebro - ativando sistemas de comunicação, redes de informação - e os corpos - em sistemas de bem-estar, atividades monitoradas - com o objetivo de atingir um estado de alienação independente do sentido da vida, do desejo de criar.

"O controle da sociedade sobre os indivíduos não é feito apenas por meio da consciência ou da ideologia, mas no corpo e pelo corpo. Assim, nesta sociedade de controle capitalista, a biopolítica - exercício do biopoder - visa regulamentar a vida não qualificada politicamente, incidindo então sobre a produção, reprodução e movimentos da vida, e criando um imenso campo de imanência. Por excelência, ela se faz sobre o biológico, sobre o somático, sobre o subjetivo, sobre o cultural” (Negri \& Hardt, 2003, p. 46), indo com isso além das versões do materialismo histórico que considerava o problema do poder e da reprodução social apenas num nível superestrutural (Foucault, 1994), separado do nível real e básico da produção da vida e dos seus movimentos.

Ao longo de toda a tradição moderna o poder constituído sempre tentou anular a potência da multidão - compreendida como um coletivo de singularidades capaz de exercer sua potência instituinte - pois ela era vista como causa de anarquia social, de dispersão, da formação de bandos e da instalação do caos. O Estado Moderno transcendente, soberano, trataria de impor - de fora e de cima - uma ordem que sacrificava esta multidão de singularidades na sua diferença.

Se a sociedade do panótico - a sociedade disciplinar - produziu indivíduos disciplinados e corpos dóceis, caracterizando um anátomo-poder, a sociedade do mercado ou do capital globalizado - sociedade de controle - produz comportamentos, controla os movimentos e o tempo e, portanto, gere os impulsos dos sujeitos, aumentando-os ou diminuindo-os, caracterizando com isso o funcionamento do modelo do biopoder, que, como vimos, é o poder difuso e infiltrante sobre a vida.

Este biopoder desvanece e mesmo desfaz fronteiras. Como poderíamos pensá-lo ao nível de sua implicação com os registros psicanalíticos do real, do simbólico e do imaginário? Da pulsão como conceito-limite, onde a força de origem corporal exige a formação do psíquico, o que pensar quando o modo de funcionamento vertical ou transcendente do simbólico sobre o real do corpo vacila pelo desmoronamento de sua eficácia?

Se o indivíduo é produto da sociedade disciplinar, qual será o sujeito da sociedade de controle? A disciplinarização intensiva e difusa de corpos que 


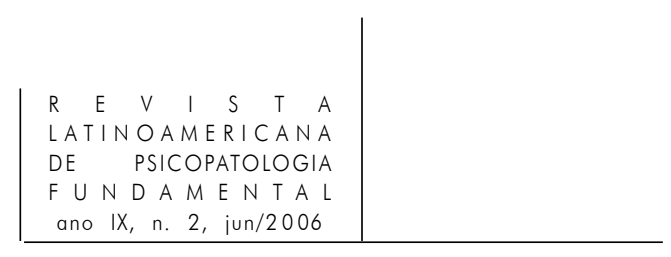

caracteriza a sociedade de controle atinge o psíquico - a alma - pela produção de afetos: medo, desamparo, angústia de dessubjetivação/pânico, tornando o indivíduo menos do que um subjectum - o assujeitado da sociedade disciplinar tornando-o um dessujeito por uma disponibilização intensa do real do qual ele é parte e onde não há endereçamento para que ele faça o reconhecimento de seu ser sujeito - mesmo que assujeitado -, passando de funcionário público a consumidor de drogas, a bulímico, a jovem alcoólatra, a "um grão de milho” ... onde consuma sua indiferenciação, como pode ser visto a seguir.

\section{A dessubjetivação e o seu pânico}

Em Jugar la palabra, livro instigante do psicanalista argentino Luiz Vicente Miguelez, no capítulo significativamente intitulado "El desamparo ante el Otro", o autor refere-se à historieta que A. Didier Weil narra em Os três tempos da lei.

Um louco estava internado em um manicômio por acreditar ser um grão de milho. Passado algum tempo, o louco deixou de acreditar nisso e o psiquiatra lhe dá alta. Ao sair do hospício, eis que encontra uma galinha. Ficou petrificado, sem palavras. Em pânico, pôs-se a correr, voltando ao hospício. Ao consultarse novamente com o psiquiatra, contou desesperado seu encontro com $A$ galinha. "Mas, homem!" - disse o psiquiatra - "você já está curado e sabe que não é um 'grão de milho'”. "Sim, Doutor, eu sei... Mas será que ela sabe?”.

Comenta Miguelez que o humor da história, ao despertar o nosso riso, contribui para frear este gozo do Outro que de alguma forma somos obrigados a sustentar. Acredito que seja possível, através de nossas meditações coletivas e solitárias, encontrar condições para barrá-lo na sua desmesura atual. Para realizar esta tentativa, algumas questões se impõem. Procuro indicar algumas ao longo deste estudo.

Qual seria a diferença, se houver, com a cena do louva-a-deus e o sujeito da modernidade de Lacan, narrada no Seminário de 1962-63, isto é, há quase 50 anos? Lembro aqui que o nome deste inseto deve-se ao fato de sua postura evocar a de um homem em oração.

Lembro também que em Temor e tremor, Kierkegaard diz que "todo homem que não age como Abraão diante do sacrifício de seu filho Isaac porta a angústia”. Ou seja, na ausência da fé, o homem, diante do gozo do Outro, é tomado pela angústia.

Naquele limiar da contemporaneidade - compreendida como ethos marcado pelo acontecimento tecnológico da bomba de Nagasaki e Hiroshima - o Outro como um gigantesco louva-a-deus nos fala de uma cultura opaca aos valores divinos, na esteira da proclamação da morte de Deus por Nietzsche, mas ainda 


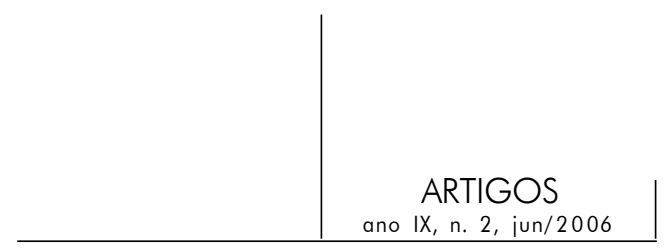

assim guardando em seu nome - louva-a-deus ${ }^{7}$ - uma referência a eles. O sujeito não mais garantido pelos valores de legitimação dos grandes discursos (entre eles o religioso e o filosófico clássico) se angustia. Sendo esta angústia o sinal de uma despossessão subjetiva radical por vir, no seu auto-engendramento com as transformações ocorridas posteriormente ao nível da cultura, configurando o acontecimento das crises de pânico no contexto do aumento abusivo do malestar no último quartel do século XX e início do XXI.

Parece evidente que esta cena da angústia ficcionalizada por Lacan no Seminário X não corresponde ao pânico experimentado pelo nosso dessujeito/ grão de milho. Este, como membro passivo de uma cultura de disponibilização para o consumo - vontade da técnica - experimenta cada vez mais o aprofundamento da separação entre o humano e o divino, a ponto de consumar efetivamente "a morte de Deus" sob esta forma angustiada da dissolução do eu. Segundo Deleuze em Diferença e repetição, Nietzsche foi o primeiro a reconhecer na dissolução do eu o acontecimento correlativo à “morte de Deus”, capaz de torná-la efetiva. A meu ver, este “acontecimento correlativo” se consuma em nossa contemporaneidade, na passagem do século XX para o XXI, com esta angústia de dessubjetivação radical - metapsicologia do pânico -, resultante da amplificação desmesurada da dimensão constitutiva do desamparo em nossa cultura que continuamente ameaça de aniquilamento e de indiferenciação seus participantes, não permitindo que eles encontrem o reconhecimento de suas singularidades, de seus lugares próprios, nem a simples e estruturante possibilidade de endereçamento ao Outro. Fui parada recentemente na rua por uma mulher que me segurou pelos ombros, pedindo-me que a olhasse e a chamasse por seu nome.

Na privação de suas insígnias simbólicas - do reconhecimento de suas singularidades e do lugar de diferença, da possibilidade de endereçamento e de nomeação - o dessujeito encontra-se completamente perdido na imanência, indiferenciado tal como um grão de milho o é em relação a outro, e indiferente a ele como tal. Além de ameaçado de devoração por este Outro aniquilador e disponibilizador no qual se transformou a Cultura - outrora, "tesouro dos significantes" -, restando-lhe insistir neste apelo, feito agora na forma cifrada do real em uma crise de pânico.

É também em "Psicologia das massas e análise do eu” que a problemática do pânico pode se enlaçar à da perda das garantias sustentadas supostamente pelos valores das grandes narrativas e de seus fundamentos divinizados, encarnados na figura de um Grande Líder. "O pânico se instala quando os

7. Mesmo no original francês, esta metáfora se presta, pois mante-religieuse (louva-a-deus) aponta também para esta referência. 


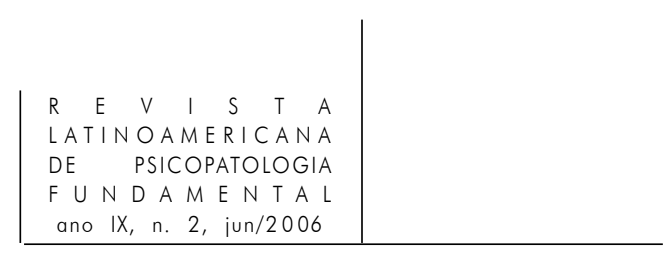

elementos do grupo descobrem subitamente que o lugar onde esperavam encontrar o Líder amado e Onipotente encontra-se irremediavelmente vazio...” . Na esteira da declaração da "morte de Deus" por Nietzsche (Dunley, 2005), Freud teria tratado o real pelo simbólico ao realizar o luto desta "morte", ou do desmoronamento dos valores divinos, através da criação da psicanálise, trazendo como tarefa trágica para o homem moderno/contemporâneo falar de seu desamparo - Hilflosigkeit - como dimensão inarredável de sua constituição, e, portanto, de sua experiência, e assumi-lo como fonte de poiesis.

Passa a ser imperativo, a meu ver, reinscrever a metapsicologia do desamparo e de sua desmesura - o pânico - numa análise da cultura. A metapsicologia do pânico - como forma de transbordamento da força pulsional que desampara o ego, levando-o a experimentar uma situação traumática ao qual ele responde com a produção automática de angústia - deve se estender para o além da physis que ressoa sob metapsicologia, pressupondo contemporânea e necessariamente a cultura como fonte de especulação, e não um além-mundo. Especulação esta que terá sempre seu lastro na clínica, impedindo-a de perder seu rumo.

220 O caráter de mímese da psicofarmacologia e sua abertura para uma utilização diferenciada dos psicofármacos

A idéia de próteses psíquicas se deve a uma das formas (a primeira) de funcionamento dos psicofármacos, a partir de sua dupla possibilidade de funcionamento: suplência/substituição de alguma função ou substância, e suplementação. Onde o suplemento é a parte que se acrescenta a um todo ou a um sistema para esclarecê-lo, aperfeiçoá-lo. Diria eu, um a mais que paradoxalmente extrairia dele o excesso de real, deixando-o livre para aparecer em sua forma ou verdade. Este é o recorte duplo da téchne em relação à physis, apresentado por Aristóteles em sua Física B.

Em uma famosa frase desse livro, Aristóteles delimita dois sentidos para a téchne ou para a mímese: "Por um lado, a téchne realiza o que a physis é incapaz de efetuar, por outro lado, ela a imita."

No primeiro sentido, a téchne é uma diferenciação da physis, embora seja ainda physis. Através da téchne, a physis se desdobra para aparecer e sair de seu ocultamento. Em outro contexto já aqui assinalado, sustentei o caráter de suplemento da téchne em relação a physis. Trata-se de extrair do real (excessivo) o seu excesso, canalizando-o, descarregando-o para que a physis (ou o real) apareça em sua verdade encoberta. Para tal, a physis necessita da téchne. Neste nível, procuro situar uma certa utilização dos psicofármacos. Ou seja, uma 
biotecnologia, que em sua função mimética de suplemento descarrega o real de seu excesso, modula-o, e de uma certa forma o aperfeiçoa.

No segundo sentido, que é o corrente na tradução latina de mimesis como imitação, e que é tomado a partir da conceituação de mimesis na Poética, a téchne é secundária, exterior à physis, que passa então a ser considerada completa em si mesmo, devendo ser duplicada ou reproduzida por uma téchne exterior e subordinada ao seu modelo.

É interessante ver nestas duas formas de mimesis, cujas possíveis funções e utilizações procuro estender à biotecnologia psicofarmacológica, sua relação com a verdade ou com as condições reais de existência do sujeito. De acordo com as análises heideggerianas a propósito da mimesis, a primeira função - de suplemento - relaciona a téchne à alétheia anterior a Platão. Seria então a função da téchne que permitiria desvelar ou desocultar aquilo que se mantém escondido, no esquecimento. Considero que esta função de suplemento dos psicofármacos é o que subjaz em certas afirmações dos psicanalistas ao assumirem a necessidade do uso de psicofármacos para "permitir a instalação (Stell) de uma psicanálise", extraindo o excesso de real, ou seja, estabelecendo um parentesco entre estas duas formas de téchne - uma, científica, e outra, trágica - a partir da idéia de suplemento e de sua relação com a verdade do sujeito

A segunda, função de suplência, relacionaria a téchne à alétheia a partir de Platão, quando ela passa a ter o sentido de homoiosis (acordo). É a operação platônica que decide a sorte da mímese como segunda, como imitação degradada. Com Descartes, seu sentido é de adaequatio (adequação), onde está em questão uma relação de equivalência entre a coisa e o seu representante, sendo, portanto, garantida a sua substituição. Estamos em meio às próteses psíquicas e à dissimulação da verdade do sujeito. Mais do que isso, ao apagamento da dimensão do desejo, que nos faz essencialmente humanos. A ponto de indiferenciadamente uma cliente chegar para uma primeira entrevista dizendo: "Tenho deficiência de dopamina." Ela era um neurônio falante, ou uma população de neurônios falantes, um simili do grão de milho. Vou chamá-la de Princesa Maíra.

\section{Conclusão: da eficácia simbólica da psicanálise}

Diante daquela objetivação em todo seu esplendor, perguntei: - Mas o que é que você sente? - Estou em depressão desde que o Guga (Gustavo Kuerten) passou a não querer mais nada comigo... Nos últimos três anos tenho seguido o Guga por onde ele vai, Roland Garros, África do Sul, Santa Catarina. Na última vez, voltei toda machucada de arame farpado... Mas é bom a gente gostar de alguém que é idolatrado... 


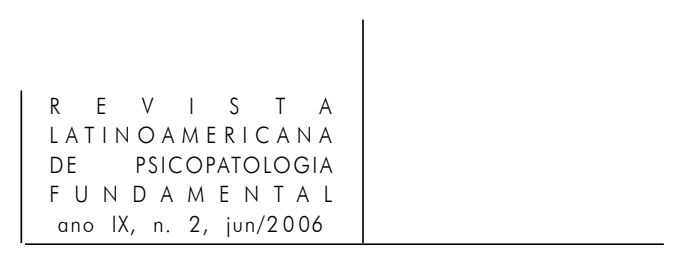

Continua esse delírio, até me dizer que havia abandonado a pintura há uns dois anos, por ter recebido de volta um quadro que mandou de presente para o Guga. Chora, e diz que ficou muito magoada. Pergunto então o que ela fazia atualmente. - Faço cerâmica. Eu sou oleira...

Ah! Quer dizer que você sabe brincar de vazio? Ela me olhou, emocionada, e disse: - Ainda bem que você é poeta... Eu estava precisando de alguém assim... O mundo ficou muito cru e a fala das pessoas também... Eu também sou artista.

Na sessão seguinte, ela me diz: - Vou te contar um segredo. Quando eu vim aqui na semana passada e você me disse que eu sabia brincar com o vazio, cheguei em casa e escrevi esta carta que eu vou ler agora para você e que fica guardada em minha bolsa. Maíra passa então a ler tristemente toda a história de sua separação.

\section{Referências}

ARISTóteles. Física. Madrid: Gredos, 1996.

Poética-Organon-Política. São Paulo: Nova Cultural, 1999.

222 Blanchot, Maurice. A grande recusa. In: A conversa infinita - I. São Paulo: Escuta, 2001. p. 73.

Bogochvol, Ariel. Sobre a psicofarmacologia. In: MagalHÃES, M. Cristina Rios (org.). Psicofarmacologia e psicanálise. São Paulo: Escuta, 2001. p. 35-61.

Chauí, Marilena. Convite à filosofia. São Paulo: Ática, 1999.

Costa Pereira, Mário Eduardo. O pânico e os fins da psicanálise: a noção de desamparo no pensamento de Lacan. Revista Percurso On-line, s/d.

A questão psicopatológica do pânico examinada à luz da noção metapsicológica de desamparo. Boletim de Novidades da Livraria Pulsional, São Paulo, ano IX, n. 86, p. 1-20, abr/1996.

Sobre o manejo de fatores psicodinâmicos no transtorno de pânico. Revista Vitrô, São Paulo, Associação Brasileira de Psiquiatria, v. I, n. 3, p. 118-23, 1997. torial, 1997.

Contribuição à psicopatologia dos ataques de pânico. São Paulo, Lemos EdiDeleuze, Giles. Diferença e repetição. Rio de Janeiro: Graal, 1968.

Foucault. Paris: Minuit, 1986.

Post-scriptum sur des sociétés de contrôle. In: Pourparleur. Paris: Minuit, 1990.

Nietzsche e a filosofia. Rio de Janeiro: Graal, 1990.

Didier-Weil, Alan. Os três tempos da lei. Rio de Janeiro: Zahar, 1998.

DunLEy, Glaucia. O silêncio da Acrópole - Freud e o Trágico. Uma ficção psicanalíti- 


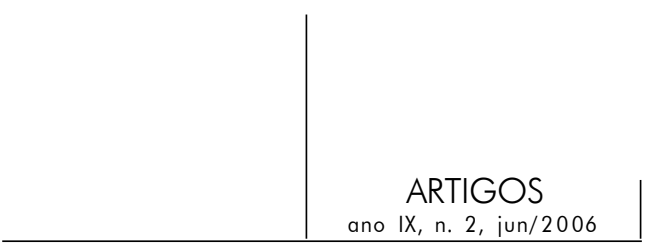

ca. Rio de Janeiro: Forense Universitária/Fiocruz, 2001.

O pensamento trágico na virada do século XX: Freud e Nietzsche. In: A festa tecnológica. O trágico e a crítica da cultura informacional. São Paulo: Escuta/Rio de Janeiro: Fiocruz, 2005. p. 183-218.

Foucault, Michel. Nietzsche, a genealogia e a história. In: Microfísica do poder. Rio de Janeiro, 1981. p. 15-37.

Dits et écrits. Paris: Gallimard, 1994.

La naissance de la médecine sociale. In: Dits et écrits. Paris: Gallimard, 1994a. p. 210.

Prefácio à transgressão. In: Dits et écrits. Paris: Gallimard, 1994b. p. 233-250.

Le nom du père. In: Dits et écrits. Paris: Gallimard, 1994c. p. 189-203.

La pensée du dehors. In: Dits et écrits. Paris: Gallimard, 1994d. p. 518-539.

Nietzsche, Freud et Marx. In: Dits et écrits. Paris: Gallimard, 1994e. p.564-579.

A vontade de saber. In: A história da sexualidade. Rio de Janeiro: Graal, 1997.

Freud, Sigmund. Obras Completas. Madrid: Biblioteca Nueva, 1973.

(1912). Totem y tabu. In: O.C. Madrid: Biblioteca Nueva, 1973. tomo II.

(1915). Los instintos y sus destinos. In: O.C. Madrid: Biblioteca Nueva, 1973. tomo II.

(1919). Lo siniestro. In: O.C. Madrid: Biblioteca Nueva, 1973. tomo II.

(1920). Mas allá del principio del placer. In: O.C. Madrid: Biblioteca Nueva, 1973. tomo III.

(1927). El porvenir de una ilusíon. In: O.C. Madrid: Biblioteca Nueva, 1973. tomo III. (1929-1930). El malestar en la cultura. In: O.C. Madrid: Biblioteca Nueva, 1973. tomo III.

(1938). Escisión del yo en el proceso de defensa. In: O.C. Madrid: Biblioteca Nueva, 1973. tomo III.

Goethe. Comentário à Poética de Aristóteles. In: Escritos sobre a literatura. Rio de Janeiro: Sette Letras, 1997.

Hegel, G. W. F. Lições de estética. Rio de Janeiro: Martins Fontes, 1945.

Heidegger, Martin (1936-1946). Dépassement de la métaphysique. In: Essais et conférences. Paris: Gallimard, 1958. p. 80-115. p. 158.

(1952). Qui veut dire penser? In: Essais et conférences. Paris: Gallimard, 1958a.

(1953). La question de la téchnique. In: Essais et conférences. Paris: Gallimard, 1958b. p. 70.

(1953a). Qui est le Zarathoustra de Nietzsche? In: Essais et conférences. Paris: Gallimard, 1958c. p. 19. 


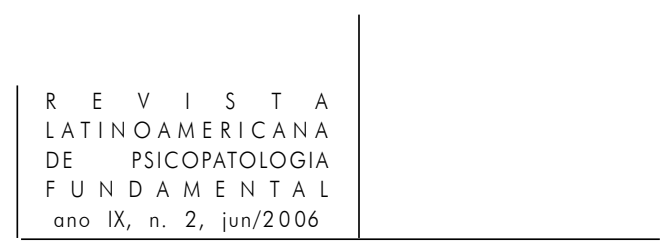

L'origine de l'oeuvre d'art. In: Chémins qui ne mènent nulle part. Paris: Gallimard, 1962. p. 13.

L'époque des conceptions de monde. In: Chémins qui ne mènent nulle part. Paris: Gallimard, 1962a. p. 99.

Le mot de Nietzsche - Dieu est mort. In: Chémins qui ne mènent nulle part. Paris: Gallimard, 1962b. p. 253.

La parole d'Anaximandre. In: Chémins qui ne mènent nulle part. Paris: Gallimard, 1962c. p. 387.

Hölderlin, Friedrich; DAstur, Françoise (orgs.). Reflexões - tragédia e modernidade. Rio de Janeiro: Relume-Dumará, 1994.

Antigone de Sophocle. Trad. Phillippe Lacoue-Labarthe. Paris: Christian Bourgois éditeur, 1988. (Collection Détroits)

Oëdipe le tyran de Sophocle. Paris: Christian Bourgois éditeur, 1998.

KIERKEGAARD, Soren. Temor e tremor. Lisboa: Guimarães Editoras,1996.

Lacoue-Labarthe, Philippe. L’imitation des modernes. Paris: Galilée, 1986.

Lebrun, Jean-Pierre. La haine de la haine. Conferência proferida em Psycorps, Paris, novembro 2002.

La mutation du lien social. Révue du CREAI (Centre Interrregional pour l’Enfance Inadaptée. Provence et al: novembro 2003).

Miguelez, Luis Vicente. Jugar la palabra - Presencias de la transferencia. Buenos Aires: Letra Viva, 2003. p. 37.

Negri, Antonio; HaRdt, Michael. Império. São Paulo: Record, 2003. p. 42-3; p. 46.

Nietzsche, Friedrich. La naissance de la philosophie à l'époque de la tragédie greque. Paris: Gallimard, 1938.

Par delà bien et mal - La généalogie de la morale. In: Oeuvres philosophiques complètes. Paris: Gallimard, 1971. v. VII.

Le gai savoi - Fragments posthumes (été 1881- été 1882). In: Oeuvres philosophiques complètes. Paris: Gallimard, 1982. v. V.

Humain, trop humain - Fragments posthumes (1876-1878). In: Oeuvres philosophiques completes. Paris: Gallimard, 1988. v. III.

Introduction aux leçons sur l'Oedipe - Roi de Sophocle. Encre Marine, 1994.

Crepúsculo dos ídolos. Rio de Janeiro: Relume-Dumará, 2000.

Assim falou Zaratustra. Curitiba: Hemus, 2000a.

Platon. La Republique. Exemplaire numéroté (n. 5268). Paris: Le club français du livre, 1954.

Pelbart, Peter Pál. O tempo não reconciliado. São Paulo: Perspectiva, 1968. 


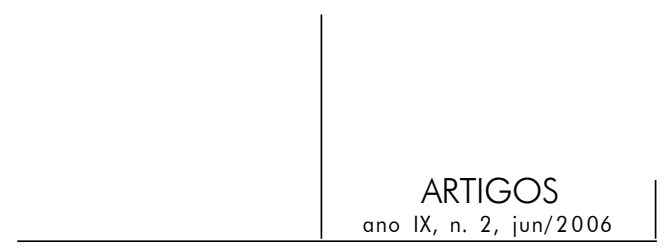

Rosset, Clement. L’objet singulier. Paris: Les Éditions de Minuit, 1979.

Vernant, Jean Pierre; Vidal Naquet, P. Mito e tragédia na Grécia Antiga. São Paulo: Perspectiva, 2002.

\section{Resumos}

Considerando la importancia del estúdio de las prótesis en la cultura informacional contemporánea, y aproximándolo del campo psicopatológico através de la idea de los psicofármacos funcionando como prótesis psíquicas, pretendo problematizar la inserción de las "nuevas tecnologías" - especialmente la psicofarmacologia - en el proyecto de longa duración de la metafísica, descortinando así la lógica de la voluntad de poder en juego y sus máscaras. Procurando formas de resistir a esta disponilización sin fin del real, por la qual el propio sujecto se ve alcanzado, objetivándose de las más variadas formas, el psicoanálisis se configura como téchne trágica, heredera de una transmisión estética y ética de la existencia, proponiéndose a restituir al hombre contemporáneo un saber sobre su propria tragicidad, por lo que seria posible afirmar un bien-vivir donde el dolor de existir no necesita permanecer encobierta.

Palabras claves: Psicofarmacología, voluntad de poder, disponibilización, panico

En considérant l'importance de l'étude des prothèses dans la culture informationelle contemporaine, et rapprochant celle-ci du champs psychopatologique par le biais de l'idée de substances psychoatives fonctionnant comme des prothèses, je prétends argumenter l'insertion des nouvelles technologies-spécialement les biotechnologies comme la psychofarmacologie-dans le projet de longue durée da la métaphysique, dévoilant par là la logique de la volonté de pouvoir en jeu, et ses masques. En essayant de résister à cette mise en disponibilité sans fin du réel, par laquelle le sujet lui-même se voit atteint par une objectivation croissante et multiple, par laquelle lui-même se rend disponible, la psychanalyse se déploie comme une téchne tragique, heritière d'une transmission estethique et étique de l'existence, et se propose à restituer à l'homme contemporain un savoir sur sa propre tragicité, par lequelle il serait possible d'affirmer un bien-vivre, òu la douleur d'exister ne serait pas réfoulée.

Mots clés: Psychofarmacologie, volonté de pouvoir, mise en disponibilité, panique

This article takes into account the importance of studying prostheses in contemporary informational culture and bringing the concept closer to the domain of psychopathology, through the idea that psychopharmacological substances often function as psychic prostheses. In this article I critically discuss the use of new 


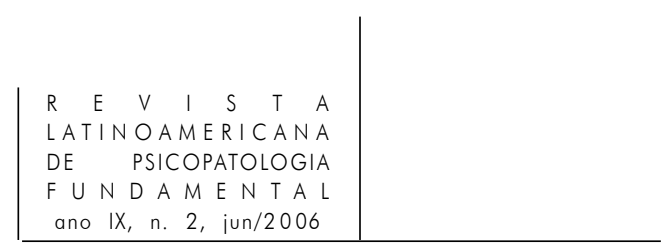

technologies, especially those of a biotechnological nature, including psychopharmacology, which could be interpreted in a long-term metaphysical project. In this sense, the logic of the will involved, is revealed. In the search for strategies to resist the endless will of the real, by which the subject himself is affected, based on the most varied forms, psychoanalysis is seen as a kind of tragic téchne, the heir to an ethical and aesthetical transmission of existence, in an attempt to give back to contemporary man an awareness of his own tragic being, through which life can be asserted as the temporality of joy, pain and finitude, therefore modulating the use of pharmacological substances which are often used as prostheses.

Key words: Psychofarmacology, will for power, willingness, panic 